IdeAs

Idées d'Amériques

15 | 2020

Eau et gestion de l'eau dans les Amériques

\title{
La gestión pública chilena después del 18-Octubre: Ideas previas y reflexiones futuras
}

\section{Rodrigo Egaña y Cristian Pliscoff}

\section{(2) OpenEdition}

\section{Journals}

Edición electrónica

URL: http://journals.openedition.org/ideas/8429

DOI: 10.4000/ideas.8429

ISSN: 1950-5701

Editor

Institut des Amériques

\section{Referencia electrónica}

Rodrigo Egaña y Cristian Pliscoff, « La gestión pública chilena después del 18-Octubre: Ideas previas y reflexiones futuras », IdeAs [En línea], 15 | 2020, Publicado el 01 marzo 2020, consultado el 25 marzo 2020. URL : http://journals.openedition.org/ideas/8429; DOI : https://doi.org/10.4000/ideas.8429

Este documento fue generado automáticamente el 25 marzo 2020.

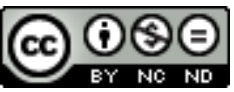

IdeAs - Idées d'Amériques est mis à disposition selon les termes de la licence Creative Commons Attribution - Pas d'Utilisation Commerciale - Pas de Modification 4.0 International. 


\title{
La gestión pública chilena después del 18-Octubre: Ideas previas y reflexiones futuras
}

\author{
Rodrigo Egaña y Cristian Pliscoff
}

1 El 18 de octubre de 2019 quedará marcado en la historia de Chile como un momento de quiebre donde muchas de las prácticas y formas de funcionamiento de nuestra sociedad fueron puestas en tela de juicio. La reacción ciudadana surge por una mezcla de abusos, injusticias y fallas del sistema, señalando a la clase política y empresarial como las y los principales culpables del estado de situación. Es indudable que este estallido es de índole multicausal y multidimensional, pero su complejidad a veces lleva a invisibilizar ciertos actores o espacios de la sociedad, que también pudiesen haber cooperado, o por lo menos no haber cumplido su rol a cabalidad, influyendo de esta manera en el resultado que se evidenció en la última parte de 2019. El presente artículo trata de analizar uno de los componentes que parece haber contribuido a este malestar, pero que no es visto con la importancia que otros actores tienen, la administración pública.

2 Si bien Chile se ubica en varios ránkings temáticos en ubicaciones de privilegio tanto en eficacia gubernamental (Banco Mundial) como en índice de percepción de la corrupción (Transparencia Internacional), no es menos cierto que existen varios elementos para sustentar la noción que desde la administración pública se instalaron o permitieron prácticas que aportaron, de alguna manera, a no transformar a la administración pública en un instrumento crucial para eliminar las desigualdades sociales. Esto por cierto no oculta el amplio número de funcionarios y funcionarias públicas que día a día trabajan para mejorar las condiciones de vida de las y los chilenos. Quizás, lo que ha ocurrido es que esos esfuerzos, podrían haber sido mucho más efectivos en disminuir las desigualdades, con condiciones de funcionamiento más óptimas. En las siguientes líneas entregamos algunas reflexiones sobre lo que se hizo, o no, en el ámbito de la administración pública, y proponemos algunas acciones que pudiesen aportar, desde este ámbito, a canalizar los esfuerzos en pos de una solución a los problemas evidentes de desempeño institucional que se han hecho evidentes. 


\section{La situación desde las instituciones públicas}

El descontento manifestado en los días previos al estallido social del 18 de octubre y en las semanas posteriores, parcialmente se basa en un juicio muy crítico y negativo sobre la forma como funciona el Estado, como está organizado para cumplir sus funciones básicas y como ha implementado diversas políticas públicas. La desconfianza hacia las instituciones públicas ha ido creciendo en el tiempo; siendo un fenómeno amplio en América Latina (Izquierdo A., et al., 2018). La situación en Chile se caracteriza por haberse ido perdiendo la confianza que se logró reconstruir con la vuelta a la democracia. Esta desconfianza se ha acrecentado por un actuar centralista del Estado, que no da espacio suficiente a las particularidades regionales (ver artículo de Marquez y Viacava en este dossier) ; con una sistemática falta de participación ciudadana en la gestión pública, que pudiera haber complementado la decreciente participación expresada en la democracia representativa ; por la existencia de procedimientos en los trámites públicos que son poco claros y frente a los cuales prácticamente no existe posibilidad de reclamar ; por la falta de regulación adecuada de los servicios públicos que son provistos por entes privados en función de concesiones otorgadas por el Estado ; por la débil fiscalización que realizan entes públicos en sus áreas de competencia; por la deficiente educación pública, las bajas pensiones, las prestaciones de salud no óptimas ; en síntesis, por la sensación de abuso permanente que experimentan la mayoría de las personas y frente a los cuales se sientes desvalidos y no apoyados por las entidades públicas.

4 El tipo de modernización de la gestión pública que ha vivido el país en los últimos 30 años, ha estado marcado por un sesgo técnico (ver artículo de Larrouqué en este dossier), más que participativo, donde profesionales y miembros de la clase política implementaron una agenda de reformas, que estuvieron muy marcadas, en los 90's por un agenda propia de la llamada Nueva Gestión Pública (Olavarría Gambi M., et al., 2011). Durante la última década del Siglo XX, la matriz de cambios y reformas a la administración pública estuvo marcada por una preminencia de la eficiencia como valor esencial del actuar público. Esto en gran medida se explicó por las condiciones sociopolíticas de la transición a la democracia, que exigía un uso racional de los recursos, en contextos de una amplia variedad de demandas sociales. La implementación de ciertas doctrinas dominantes en nuestra administración pública ha tenido efectos deseados y no deseados (Pliscoff C., 2017), cuyas consecuencias se han arrastrado bien entrado el siglo XXI. Este modelo teórico de reformas se modifica, principalmente a propósito de varias crisis políticas que vivió el gobierno, ligadas particularmente a casos de corrupción o de maladministración. Se destacan dos situaciones, la vivida en 2003 en varios casos ligados al manejo del Ministerio de Obras Públicas del sistema de concesiones de carreteras, que gatilló un proceso de ajustes en varios ámbitos, siendo uno de ellos el de selección de los Altos Directivos Públicos. El segundo caso es el de la crisis de corrupción por malos manejos en la entidad a cargo de implementar programas de deportes, que tuvo como consecuencia la implementación de una agenda pro transparencia en la gestión pública.

5 El alto nivel de politización que, a pesar de las reformas implementadas desde los 90 s en adelante, ha generado una sensación de poca importancia del mérito en la gestión pública, transformando al aparato público en un instrumento al servicio de un grupo y 
en desmedro de la sociedad en su conjunto. Este tema fue abordado parcialmente con la reforma de 2003 que creó el Sistema de Alta Dirección Pública, mecanismo que permitió un nuevo modo de contratación de las cúpulas directivas de los servicios públicos (Longo Martinez, F., 2013). Esta reforma claramente marca un quiebre en la injerencia de la clase política en la administración pública (Ramos C. y F. Scrollini, 2013), pero deja espacio para que ésta siga influyendo en esta esfera, toda vez que se concibió un modelo que combinaba confianza con mérito. La percepción es que más allá de las reformas, la política seguía teniendo un rol importante en la administración pública. De alguna forma, existía una percepción que se abusaba de la administración pública, al permitir que se contrataran directivos públicos por poco tiempo, y en algunos casos sin cumplir el estándar óptimo (Pliscoff C., 2016).

6 Pero quizás, el ámbito donde más se ha evidenciado la administración pública como problema, es en la salud pública. Más allá de un incremento sustantivo de los recursos en el sector, las cifras de listas de espera, se han tomado la opinión pública, evidenciando un mal trato permanente y regular a aquellos usuarios que más lo necesitan. Esperar tres o cuatro años por una operación urgente, debido a falta de recursos, mala información, problemas de gestión hospitalaria, entre otros miles de factores, ha generado entre los usuarios de la salud pública, la noción que, si no tengo los recursos para pagar un prestador privado, o convivo con la enfermedad, o simplemente me muero. Más allá de las significativas reformas efectuadas en varios gobiernos, destacando la implementación del AUGE durante el gobierno del Presidente Ricardo Lagos, la salud pública ha seguido siendo una de las prioridades que la ciudadanía regularmente define como prioritarias en las encuestas de opinión.

\section{De las soluciones}

7 Poder enfrentar la crisis que se manifiesta en el estallido social habido en el país, requiere asumir que el modelo socioeconómico que se ha estado implementando, ha logrado hacer que la economía crezca en forma significativa y que la pobreza se reduzca en forma notable, pero no ha logrado reducir las desigualdades que caracterizan a la sociedad chilena (PNUD, 2017).

8 Lo anterior obliga a replantearse las bases sobre las cuales se construyó este modelo y eso nos lleva tener que repensar los principios orientadores del modelo de desarrollo que se ha estado implementando en el país (ver artículo de Gárate en este dossier). Entre estos principios podemos destacar la preeminencia de la propiedad privada por sobre la estatal o colectiva, el rol subsidiario del Estado en materias económicas y sociales, el predominio del mercado como principal orientador de las decisiones económicas, el ordenamiento jurídico que asegura el resto de los principios, el valor del individualismo como base del esfuerzo por el desarrollo, la existencia de regulaciones mínimas que no interfieran en el funcionamiento de los mercados, y la mínima intervención posible del Estado.

9 Frente a esto aparece necesario proponer otros principios orientadores sobre el rol y la acción del Estado que pudieran ser considerados como constitutivos de la base de un nuevo pacto social. Entre estos podríamos destacar el necesario equilibrio entre la propiedad privada y la estatal; el rol orientador del Estado en materias de desarrollo, recuperando la capacidad para intervenir en los procesos de inversión; la participación ciudadana en la gestión pública; la transparencia y el control ciudadano sobre los 
actores públicos y privados; normas jurídicas que castiguen el abuso y las faltas a la competencia en todo tipo de ámbitos; la ética como principio orientador del actuar público; la descentralización como ordenador de la vinculación del Estado con el territorio; la equidad de género y la igualdad de trato; la eficiencia, eficacia, relevancia y economicidad en el uso de recursos públicos; la planificación indicativa como orientador del desarrollo del país; la colaboración público privada en la oferta de bienes públicos y semipúblicos, bajo estrictas regulaciones; la meritocracia en el servicio público (Egaña R., 2018).

Estos principios deberían llevarse a la práctica por medio de la confección de una agenda de reforma y modernización del Estado que cubriera diversos ámbitos, entre los cuales se podrían destacar:

- A nivel de institucionalidad será necesario completar la separación entre las instancias que definen políticas de las que las implementan.

- Instaurar una real y efectiva descentralización del nivel nacional a los niveles subnacionales, más allá de las normas actualmente existentes.

- Instalar un servicio civil profesional, inmune a la partidización, lo que obligará a revisar el estatuto administrativo. Junto a ello, avanzar en la plena aplicación de las 11 normas sobre gestión de personas del Servicio Civil.

- Alta Dirección Pública: ir a mayor autonomía del gobierno de turno; presidente del Consejo nombrado con acuerdo del Senado y por 6 años; Director Servicio Civil nombrado por el Consejo. Revisar causales de despido de altos directivos, excluyendo la mera desconfianza política del gobierno de turno.

- Revisar estructura y niveles de remuneraciones en el sector estatal, buscando alcanzar mayor equidad.

- Modernizar procedimientos administrativos, crear Tribunales Contencioso Administrativo; hacer obligatoria aplicación de dicha ley con sanciones graves a infracciones.

- Modernizar la Contraloría General de la República, con nueva ley orgánica, repensando su rol en un estado regulador mas que productor directo de bienes y servicios.

- Profundizar participación ciudadana, haciendo obligatoria la participación consultiva y definir asuntos en que sea resolutiva.

- Aumentar drásticamente sanciones por corrupción y faltas a la probidad.

- Crear sistema nacional de planificación indicativa, como orientador del desarrollo nacional.

- Revisar normas de ley de concesiones para que se establezca nivel máximo de rentabilidad en provisión de bienes públicos y repensar el sistema de alianzas público - privadas para la provisión de dichos bienes.

- Avanzar en el gobierno digital aplicado a todos los ámbitos de la gestión pública, buscando llegar a una gestión ambientalmente sustentable.

- Avanzar en el rediseño de políticas públicas basadas en un enfoque de derechos, con especial énfasis en la superación de inequidades y desigualdades, lo que deberá expresarse a niveles de programas y proyectos de interés públicos. Junto a lo anterior, establecer una instancia autónoma en el estado, destinada a realizar la evaluación de las políticas públicas.

\section{A modo de cierre}

11 El tema de reforma y modernización del estado ha sido parte de las agendas de todos los gobiernos desde 1990. También el actual gobierno propuso en Julio del 2019 una Agenda de Modernización del Estado (Gobierno de Chile, 2019) y ha creado un Consejo 
Asesor permanente en la materia. Ciertamente las prioridades fijadas en dicha agenda deberían ser drásticamente modificadas en línea con ideas como las propuestas en este artículo, a propósito del nuevo contexto político y social que enfrenta el país. La definición de una nueva agenda debería necesariamente ser una política de Estado, consensuada con actores políticos, académicos, sindicales y sociedad civil, que reflejara las urgencias identificadas y las demandas planteadas.

\section{BIBLIOGRAFÍA}

Egaña, Rodrigo, « Reforma del estado 3.0: desafíos para el tiempo presente », Estado, Gobierno y Gestión Pública, n³1, 2018, p.5-41.

Gobierno de Chile, Agenda de Modernización del Estado. Julio 2019, Presidencia, Ministerio de Hacienda y Ministerio Secretaría General de la Presidencia, Santiago, 2019, https://cdn.digital.gob.cl/

filer_public/d3/e3/d3e3bb10-4ad2-4df8-adfa-b4ff69a658b6/agenda-de-modernizacion-delestado.pdf, consultado el 11/03/2020

Izquierdo, Alejandro, Pessino, Carola, \& Vuletin, Guillermo, Mejor gasto para mejores vidas: cómo América Latina y el Caribe puede hacer más con menos (Vol. 10), Washington DC, Inter-American Development Bank, 2018.

Longo Martínez, Francisco, « Diez años de alta dirección pública en Chile », in XVIII Congreso Internacional del CLAD sobre la Reforma del Estado y de la Administración Pública, 2013.

Olavarría Gambi, Mauricio, Navarrete Yáñez, Bernardo, \& Figueroa Huencho, Verónica « ¿Cómo se formulan las políticas públicas en Chile?: Evidencia desde un estudio de caso », Política y Gobierno, vol.18, n¹, 2011, p.109-154.

Pliscoff, Cristián, « Alta Dirección Pública: Elementos teóricos y reflexiones a partir del caso chileno », in I. Cienfuegos y F. Penaglia (eds.), Manual de Administración Pública, Santiago, RIL Editores, 2016, p. 383-401.

Pliscoff, Cristián, «Implementando la nueva gestión pública: Problemas y desafíos a la ética pública. El caso chileno », Convergencia, vol.24, n73, 2017, p.141-164.

PNUD, Desiguales: Orígenes, cambios y desafíos de la brecha social en Chile, Santiago, Programa de las Naciones Unidas para el Desarrollo (PNUD), 2017.

Ramos, Conrado, Scrollini, Fabrizio, « Los nuevos acuerdos entre políticos y servidores públicos en la alta dirección pública en Chile y Uruguay ». Revista Uruguaya de Ciencia Política, vol.22, n¹, 2013, p.11-36.

\section{AUTORES}

\section{RODRIGO EGAÑA}

Rodrigo Egaña: INAP-Universidad de Chile regana@iap.uchile.cl 


\section{CRISTIAN PLISCOFF}

Cristian Pliscoff: INAP-Universidad de Chile cpliscof@iap.uchile.cl 